\title{
Understanding challenges and success factors in creating a data-driven culture
}

\author{
Myrthe Storm \\ KPMG/University of Amsterdam Business School \\ myrthe.storm3@gmail.com
}

\author{
Hans P. Borgman \\ University of Amsterdam Business School \\ h.p.borgman@uva.nl
}

\begin{abstract}
Increasingly, organizations aspire to practices of datadriven decision making. The necessary transformation to a data-driven culture poses challenges, and this paper explores these as well as success factors. The study is based on six in-depth case studies of organizations that are in different phases of their transformation towards a data-driven organization. Propositions derived from change management and digital transformation literature guide our exploration. Our findings show how challenges and responses differ across the various stages of the transformation. Challenges include resistance to new technology; rigid organizational structures; and too little focus on usable analyses. Success factors include clear communication and leading by example by topmanagement; showing relevant and clear results of the transformation; and openness to experimentation. A discussion of implications and future research directions rounds off the paper.
\end{abstract}

\section{Introduction}

Becoming data-driven is stated as one of the top priorities for organizations for the last 10 years [1], [2]. Numbers show clearly benefits of being datadriven. Companies who base their decisions on evidence are on average $5 \%$ more productive and $6 \%$ more profitable than their competitors [3]. Despite the high priority of becoming data-driven, businesses are struggling to fully leverage investments in digital capabilities when undergoing the transformation [4]. The percentage of firms that identify themselves as data-driven has even declined in each of the last three years [5], [6]. According to these studies, too many conversations about data and analytics are focused on technology. Although having the right technology is essential, many executives underestimate the importance of people to build a successful data and analytics function [5], [3], [7]. Becoming data-driven is about building capabilities, tools and most important a culture that is acting on data [8]. Findings of a 2019 NewVantage Partners survey show that the difficulty to change organizational culture is seen as the main obstacle in transformations towards data-driven organizations [5]. Hence, to become a data-driven organization, good execution of organizational change is a prerequisite to see valuable benefits from investments in data and analytics. However, organizational change in digital transformation differs in scope and complexity with previous organizational changes [9].

Our study builds on the widely cited datadriven transformation model developed by Davenport (2010), which is also embraced by practitioners; the socalled DELTA model [10]. In this model, five maturity phases (from 'analytically impaired' to 'analytical competitor') are distinguished across five dimensions: Data, Enterprise, Leadership, Targets and Analysts. Organizations (or departments) can be positioned at different maturity levels for each dimension and can thus benchmark themselves. Although the DELTA model has great value when assessing and guiding transformations, it does not include culture (being datadriven) as one of its dimensions. Davenport has since acknowledged its crucial role and is also involved in the aforementioned NVP study, but studies that investigate the role of culture are still lacking.

Widely used change models provide an understanding of the phases in organizational change [11], [12], [13], [9]. However, the scope and complexity of digital transformations and the role of culture has so far received little attention and more research is required [2], [7], [14]. Therefore, our study explores the addition of a culture dimension to datadriven transformation models, building on the DELTA model, with an explicit focus on change management.

This leads to our research question: How can we understand the challenges and typical responses of data-driven culture in transformations towards datadriven organizations? 
In this study a multiple-case design is executed to unveil new and embedded insights. Six cases are studied by means of in-depth interviews. Data collection is guided by propositions derived from literature. This is discussed in section 2. The third section includes the research method after which, in section 4, an overview of the cases is provided. A cross-case analysis is presented in section 5 followed by section 6 in which the findings and implications are discussed along with suggestions for future research. This research is of academic relevance as it extends research on data-driven transformations by exploring culture as a critical factor of data-driven transformations. Managerial relevance is closely related to this, and our positioning of the study as an extension to the practically acclaimed DELTA model adds to this.

\section{Literature review}

In this section the main concepts about datadriven transformations are discussed. Thereafter, theories on organizational change are reviewed and propositions are formulated to guide the investigation and attain the purpose of this study.

\subsection{Data-driven organizations}

Being an analytical and data-driven organization means using data and analytics that results into better decisions (Davenport et al., 2010). According to multiple researchers (KPMG, Deloitte, McKinsey) using analytics pays off, as it results into faster and better decision-making, increased productivity, lower costs, reducing of risks and at the end to financial improvements. High performing analytical companies make double the amount of decisions for day-to-day operations comparing to low performing analytical companies. Decisions based on rough analysis and effective use of data analytics is perceived as their key differentiator [15]. The effect of Big data capabilities [2] and Business analytic capabilities on firm performance are covered in the literature [16].

However, recent research shows that, despite embedding Business Intelligence tools and developing quantitative models, most decisions are still based on intuition, rather than on facts [8]. These decisions are mostly supported by experience, and argumentation such as: "We did this also last year". To become datadriven, different skill sets of employees are needed. It requires a change in the core of everyday tasks that must be learned alongside the job [10]. Often a threatening feeling occurs to employees when technological systems and new working methods cross their paths. The main barriers companies are facing when implementing digital initiatives, such as a data and analytics function, is to create a culture in which all employees are committed to succeed [5].

To visualize and understand the progress of the transformation towards a data-driven organization maturity models are frequently used [17]. These models help organizations to assess the current situation, provide a guide for improvement and to use it as a benchmark. A variety of models have been developed and there is a growing interest at academic level [18]. Several models for data-driven maturity have been developed. The model of Saxena and Srinivasan (2013) [19] distinguish three dimensions: culture, capability and technology, whether Cosic, Shanks and Maynard (2012) developed a business analytics capability maturity model with four areas: culture, people, governance and technology [16]. Another example is a model from Comuzzi and Patel (2016), who developed a model concerning big data maturity including six stages and five domains (data, organization, strategic alignment, information technology and governance) [20]. In this study the DELTA model developed by Davenport is used, as discussed in the introduction.

One of the cited challenges in transformations towards data-driven maturity is creating a culture [21], [3], [5], [7]. In the next section theories about phases in change management are reviewed and combined with current insights regarding data-driven transformations and data-driven culture in order to derive propositions.

\subsection{Data-driven culture and transformations}

Various change models provide an understanding of the different phases within change management. Major adopted models that have been effectively applied to businesses and industries with the aim of dealing with change and transition are Lewin's unfreeze-move-refreeze model [11], the stages of change model developed by Prochaska and DiClemente [13], Prosci's five levels of change maturity and Bridges' transition model [22].

In change processes, the first phase is described as a phase in which little or no change management is applied [22]. There is no acknowledgement that there is a problem and that behavior needs to be changed, and the majority of the people tends to become uncomfortable when any change occurs [11], [9]. In the second phase, change management initiatives takes place in isolated projects [22]. People become aware and acknowledge the need to change [13], [12], [9]. The third phase is described as a phase in which a comprehensive approach for 
managing change is applied in multiple projects [22]. At this level, people begin to embrace the change and understand its importance [9]. The desire to participate and support for change occurs [12]. In the fourth phase organization-wide standards and methods are deployed for managing and leading the change. During this phase the actual change of behavior takes place and people may start to experience the benefits of the change [9]. The last maturity level is described as the fifth phase in which the change is evident in all levels of the organization and implemented in a day-to-day basis [22], [11], [12], [13].

Various authors have stressed that being able to manage organizational change on constant base is a prerequisite to keep up with competition [23], [24]. A critical factor in organizational change and especially one that is challenged in data-driven transformations is the role of the board [25], [3]. Leaders have an essential role in designing and implementing organizational culture that contributes to the extent in which the organization becomes data-driven [24], [25], [26], [27]. A shared vision developed by leaders is considered to inspire and motivate employees for organizational change [28], [29], [30]. When describing effective change programs scholars suggested to start initiatives coming from the board in which the urgency is established and activities that has to be undertaken are communicated [31]. To succeed in a data-driven transformation clear communication from top-management of what data-driven working looks like is required [3]. Besides, behavior of leaders is considered as a central component in the transformation [32]. To ensure employees adapt their behavior to desired actions leaders should work according to the new culture they wish to see [33]. This helps employees to identify what, why and how an interchange is taking place [34]. As social reinforcement of others is affecting the belief and opinion someone has, likeminded employees from other business units will follow and every corner will be touched [35]. In all maturity phases leadership occupies an important role in the change process to a data-driven culture. Given the prior identified challenges concerning the role of the top-management, the following proposition is determined:

Proposition 1: The first response of a datadriven culture to challenges in data-driven transformations is the responsibility of topmanagement for communicating the change and taking an exemplary role.

Another response of data-driven culture is showing concrete results and create an understanding of the relevance of data-driven working. Particular in maturity phases 2 and 3 this is an important challenge in order let people acknowledge the need to change and create desire for participating [9], [11], [12]. In Kotter's model of change a generic perspective on organizational change is described based on a uniform framework of eight steps [36]. The first step is increasing urgency after which in a later stadium shortterm wins has to be communicated [36]. The latest adaptation of Kotter's work [37]. suggests to work with a dual operating system wherein the existing management-driven hierarchy is complemented by a network-like structure of individuals in order to implement a new strategy. Kotter stresses the importance of creating a sense of urgency to let more people participate and increase the pace of change. People should believe and feel that they contribute to a better future by doing their work. Particular challenged in a data-driven transformation is determining logic behind decisions and the meaning of evidence [7]. In order to create an understanding of the relevance, Cosic, Shanks and Maynard expressed communicating and explaining benefits of data-driven decision-making as critical factor [16]. Resistance to adoption of organizational change occurs when people are not able to visualize the new reality. Therefore, Kotter suggested to assign volunteers who feel committed to carry out this strategy to others [37]. Given these theories the second proposition is developed:

Proposition 2: The second response is showing concrete results and creating understanding of the relevance of data-driven decision-making by using change agents.

After showing concrete results and providing an understanding of the relevance of data-driven working, it is important to let organizations experiment with these new ways of working in order to actually change behavior [7]. Therefore, openness to experimentation and encouraging of continuous learning is needed [7], [38], [39]. Kotter and Schlesinger (1989) emphasized the importance of participation of employees to deal with resistance to change. Organizations have to make sure that employees are involved in the transformation [39]. In data-driven transformations Pfeffer and Sutton suggest to let managers experiment with new ideas and reward those who learn from these efforts, even if an experiment itself fails [7]. J. Shook suggested to create innovation initiatives where employees can experience the new way of working. Hereby, it is critical to enable safe failure and learning opportunities [33]. As a result hard truths about what works and what doesn't are provided that enables the organization to make smart decisions on pressing issues. Given the prior identified challenges concerning a data-driven culture the following proposition is determined: 
Proposition 3: The third response of a datadriven culture to challenges in data-driven transformations is creating openness for experimentation and innovative initiatives.

To explore the data and examine the propositions the DELTA maturity model of Davenport (2010) is used in this study as a guiding instrument. Though, it might be argued that a maturity model oversimplifies the reality [40]. Hence, the use of a maturity model in this research is not for the purpose of predicting a step-by-step approach. Rather, the different phases of maturity are used to simplify the complex process of defining different levels of analytical success. It helps to determine the drivers for success and the challenges at various organizations in certain phases in a clear and consistent way.

\section{Research method}

The purpose of this study is to gain a better understanding of a data-driven culture, and especially what challenges and drivers are in certain phases. In order to uncover insights and unveil unforeseen patterns a case study approach is selected [41]. Studying multiple cases increases the reliability and validity of the study [42]. A total of six cases have been purposively selected and studied in-depth, all facing a transformation towards a data-driven organization. The primary data-collection method for this study is the use of semi-structured interviews, supplemented with document analysis. The interview protocol is structured around five substantive themes including the three propositions as discussed in previous sections, an overview of the transformation, and it covers possible success factors and challenges. However, to keep the exploratory aspect of the study, emergent topics and unique case characteristics that came up during the interview were allowed to further elaborated on. The study comprises a holistic design, as within each case three employees from different levels are interviewed: a manager who is in the lead of the transformation and two employees who are part of (or 'undergo') the transformation. These positions were selected to provide a comprehensive view of the transformation and a good understanding of the culture in each case [43]. To obtain information about organizational circumstances in different levels of data-driven maturity the sample includes two low analytical, two middle and two high analytical cases to facilitate comparison [44]. The selected cases are cross-industry with no further intention to show industry differences. There are no names provided due to privacy concerns expressed by the participating organizations. In total eighteen interviews were conducted after which they were transcribed, analyzed and coded. As this study is guided by a deductive approach a start list of codes was generated derived from theory. However, during the analysis some codes were redefined as well as new codes were developed. Relevant success factors and challenges are driven by an inductive approach. Finally, the cases were analyzed based on a cross-case comparison.

\section{Cases}

The six cases concern organizations that have been actively pursuing a data driven transformation for at least 4 years. In all cases this path has included the start of multiple initiatives around analytics, Big Data, etc. The cases have been anonymized at the request of the participating organizations. An overall maturity level has been developed for each case as the average for the score across all DELTA dimensions, and they have been ranked and labeled from A (least mature) to $\mathrm{F}$ (most mature).

Cases A and B are in phase 2. The transformation is in an early phase, which means that employees within these organizations are starting to become aware of the need to change [13], [12]. However, change initiatives take place in isolated projects [22]. Case C and D are in phase 3. There is desire to participate and support for change among employees and in both firms a comprehensive approach is applied in multiple projects across the organization [22]. Case $\mathrm{E}$ and $\mathrm{F}$ are currently in phase 4 of their maturity. Within these firms, organization-wide standards are deployed [22] and many employees work in a data-driven way. The organizational structure of analytical teams in cases $\mathrm{C}$, $\mathrm{D}, \mathrm{E}$ and $\mathrm{F}$ is decentralized, and in cases $\mathrm{A}$ and $\mathrm{B}$ centralized. This general description of the cases provides context for the following cross-case analysis. An overview is presented in table 1 .

Table 1: Case study overview

\begin{tabular}{|l|l|l|l|}
\hline $\begin{array}{l}\text { Case } \\
\text { (\# of inter- } \\
\text { views) }\end{array}$ & Industry & $\begin{array}{l}\text { Data-driven } \\
\text { culture } \\
\text { maturity } \\
\text { phase }\end{array}$ & $\begin{array}{l}\text { Organizational } \\
\text { structure of } \\
\text { analytics }\end{array}$ \\
\hline A (3) & Real Estate & 2 & Centralized \\
\hline B (3) & Construction & 2 & Centralized \\
\hline C (3) & Banking & 3 & Federated \\
\hline D (3) & Banking & 3 & Federated \\
\hline E (3) & Telecom & 4 & Federated \\
\hline F (3) & Technology & 4 & Federated \\
\hline
\end{tabular}

\section{Cross-case analysis}

In the following section a cross-case analysis is performed in which findings from each proposition are examined and compared to ultimately answer the 
research question [42]. To refrain from subjective interpretations and increase the reliability the analysis is assisted by literature and quotations of interviewees [42]. Prior to the cross-case analysis an overview of the degree in which the propositions are supported per case is shown in table 2 (from 0 meaning no support, to ++ + meaning strong support). This is followed by a crosscase analysis for each proposition, illustrated by relevant quotes from the interviews.

Table 2: Cross-case analysis

\begin{tabular}{|l|l|l|l|l|l|l|}
\hline Proposition & $\begin{array}{l}\text { Case } \\
\text { A }\end{array}$ & $\begin{array}{l}\text { Case } \\
\text { B }\end{array}$ & $\begin{array}{l}\text { Case } \\
\text { C }\end{array}$ & $\begin{array}{l}\text { Case } \\
\text { D }\end{array}$ & $\begin{array}{l}\text { Case } \\
\text { E }\end{array}$ & $\begin{array}{l}\text { Case } \\
\text { F }\end{array}$ \\
\hline $\begin{array}{l}\text { Maturity } \\
\text { level }\end{array}$ & $\mathbf{2}$ & $\mathbf{2}$ & $\mathbf{3}$ & $\mathbf{3}$ & $\mathbf{4}$ & $\mathbf{4}$ \\
\hline P1 & +++ & +++ & +++ & +++ & +++ & +++ \\
\hline P2 & + & ++ & ++ & +++ & +++ & +++ \\
\hline P3 & ++ & + & + & ++ & ++ & +++ \\
\hline
\end{tabular}

\subsection{P1: Clear communication and an exemplary role of top-management}

This section illustrates that clear communication and an exemplary role from topmanagement are important to create a data-driven culture in data-driven transformations [3]. Overall, we find strong support for the first proposition across all six cases. The critical role of top-management is exemplified in case B: "During the management consultation our $\mathrm{CFO}$ is always very enthusiastic about new developments. He creates a kind of sphere in the top-layer of the organization allowing people in other layers to get started with it." However, enthusiasm is not enough in order to create and affirm a culture. The same interviewee in case B also refers to the importance of taking an exemplary role as board member in working data-driven. He explains it as follows: "I think the board barely takes a look at the reports in Qlikview. They prefer to just have it printed in front of them. As far as I am concerned, the board serves as an example. If they still work with printed A4 including a few graphs, I am like: come on, this just radiates downwards. If employees don't feel pushed by layers above them, then it just won't happen." In case $\mathrm{A}$ and $\mathrm{C}$ this is also expressed as a critical challenge in building a culture in which employees from different levels use data to build their argumentations. In case F one interviewee expressed this as well by explaining how it contributes to move forwards in their maturity of a data-driven culture: "Due to promotion by our topmanagement the data-driven transformation comes alive. It also puts pressure on those HR-managers to work in a data-driven way". This is in line with the literature in which behavior from leaders is described as a central component in the transformation process [32]. In case $D$ the influence of pressure from management on awareness among employees is highlighted: "In general there is awareness, and that's because our management is pushing it". This pressure can be carried out specifically in challenging employees by asking for evidence in order to stimulate them to work more data-driven [3]. A manager in case E stressed this by stating: "A manager must challenge their employees. So by asking questions such as: 'Why do you interpret it like this?' 'What does it mean?' How do you know this is going to work?' By asking good questions someone learns to think that way". A manager in case A expressed his believe of a top-down approach by stating: "I am convinced it has to be carried out by the directors of the organization and that it has to be demonstrated top-down". Although the role of top-management is of critical importance, change can also be encouraged by other levels across the organization. One interviewee from case F stated: "You can also steer it from below by coming up with relevant initiatives driven by data, that makes it for fellow colleagues increasingly plausible to also base their decisions on data." This corresponds with the network-like structure Kotter suggests [37].

All in all, the top-down approach is considered as important by all six cases in order to drive the change [24], but this can be complemented by a network like structure [37].

\subsection{P2: Showing concrete results and relevance}

This section highlights that firms transitioning to data-driven focus on showing concrete results and clarification of how data contributes to better performance when realizing a data-driven culture. This is generally in line with findings from change management models that have a less explicit focus on cultural change [37], [7]. One interviewee in case C stated: "The core is creating awareness of what the relevance is of data-driven working. You have to motivate people by showing them it yields something for them". This is expressed in case D as well. People should believe and feel they contribute to a better future by doing their work [37]. When this feeling is missing it hinders employees in their motivation to make the shift from making decisions based on intuition or gut-feeling to data-driven argumentations. An interviewee from case B is stating: "I think data isn't used by a lot of employees, because they're unaware of the possibilities data can offer them".

Besides the hype of big data among executives and data-scientists, it is perceived as a new and complicated concept for many employees in other functions. In cases A, B, C and D interviewees 
expressed the importance of showing how it benefits these employees. In case $\mathrm{D}$, one interviewee states: "To realize a change it is important to demonstrate results to the department and show them it will benefit them all. And in addition to just saying it, you must be able to show it". An understanding of how data contributes to work performance results in growing affinity with data [16]. In cases that are at higher maturity levels it is even expressed as one of the drivers. In the words of one interviewee of case F: "They get more and more affinity with the possibilities of data, because they see moments of use and great ideas. I notice that very clearly". It is also expressed by an interviewee in case $\mathrm{D}$ as a personal reason why she works data-driven: " $\mathrm{An}$ important reason for me to work data-driven is because I think your decisions will be more effective when they are based on data".

In addition, being able to measure and show actual effects of certain activities also in increases the demand for data-driven argumentations. In case $\mathrm{E}$ one interviewee stated: "By showing the effect of certain media deployment in this case, the demand for datadriven decisions will increase. By doing so, it becomes less likely to choose for outdoor media while the effect cannot be made clear." This network effect is paying off as choices based on gut-feeling or intuition become harder to motivate when a colleague is able to demonstrate the effect of certain activities [37]. Interviewees from case B and case $F$ express the need for change agents to demonstrate the data-driven initiatives: "When introducing these kind of initiatives, you need ambassadors who share their believe and enthusiasm to the rest of the organization".

\subsection{P3: Openness towards experimentation and innovation}

To be able to show results and create awareness of the relevance of data, openness towards experimentation and initiatives is needed [7], [38]. Cases who are in the initial phase of the maturity of a data-driven culture confirmed the importance of experimentation. One interviewee from case A stated: "At the moment you experiment with data yourself, then I also will see its relevance". In case E the handson mentality and 'just doing it' has created a mindset to work in a data-driven way. This is in line with the literature in which Kotter and Schlesinger suggested that organizations have to make sure to let employees participate in the transformation [39]. As well as for the cases who are in the initial phase of the transformation as for companies who already reached the fourth maturity level, initiatives concerning data has worked to make steps forward in the transformation. This is described by a success story of Case C, where they introduced a Data-Lab to do experiments which made them able to demonstrate results derived from data in order to show the relevance. In addition, he said: "This also has worked for other departments, just experimenting to see what is possible". Initiatives should not only refer to experiments, but also to educational sessions. In all six cases it is acknowledged that taking employees by the hand and explain them how it works will improve their awareness. Finally, enabling safe failure and learning opportunities as suggested by J. Shook [33], is confirmed as an interviewee from case F stated: "I try to make it accessible for other colleagues. For example, I am quite often invited for meetings, because it's a safe environment for them to let me explain how it works, as they actually don't get it. Even so, I notice it really improved their willingness to work with data".

\subsection{Identification of challenges and success factors per maturity level}

Based on a cross-case analysis relevant success factors and challenges are identified for maturity levels 2,3 and 4 . The success factors determines the main drivers that brings the organization to that certain maturity phase of a datadriven culture. The challenges on the other hand, describes any barriers or struggles companies are facing when trying to move forward to the next phase. Table 3 provide an overview of the success factors and barriers after which the findings are discussed.

Table 3: success factors and challenges per maturity phase

\begin{tabular}{|c|c|c|c|}
\hline Factors & $\begin{array}{l}\text { Maturity phase } \\
2 \\
(\mathrm{~A}, \mathrm{~B})\end{array}$ & $\begin{array}{l}\text { Maturity } \\
\text { phase 3 } \\
(C, D) \\
\end{array}$ & $\begin{array}{l}\text { Maturity phase } \\
4 \\
\text { (E, F) }\end{array}$ \\
\hline $\begin{array}{l}\text { Success } \\
\text { factors }\end{array}$ & $\begin{array}{l}\text { - Follow clear } \\
\text { strategy } \\
\text { - Pressure from } \\
\text { clients }\end{array}$ & $\begin{array}{l}\text { - External } \\
\text { pressure } \\
\text { - Defining } \\
\text { KPI's } \\
\text { - Young } \\
\text { generation } \\
\text { - Off-site and } \\
\text { sessions }\end{array}$ & $\begin{array}{l}\text {-Organizational } \\
\text { goals are all } \\
\text { data-driven } \\
\text { - Push from } \\
\text { management }\end{array}$ \\
\hline $\begin{array}{l}\text { Challen } \\
\text { ges }\end{array}$ & $\begin{array}{l}\text { - Resistance to } \\
\text { new technology } \\
\text { - Making } \\
\text { analysis usable }\end{array}$ & $\begin{array}{l}\text {-Organiza- } \\
\text { tional } \\
\text { structure } \\
\text { - Lack of time }\end{array}$ & $\begin{array}{l}\text { - Lack of skills } \\
\text { in certain } \\
\text { departments }\end{array}$ \\
\hline
\end{tabular}

The main driver to initially start the transformation successfully is identified by case B as following clear strategic strategy. To quote the interviewee from case A: "What has worked for us is to 
follow a clear strategic route that has put much more focus within the organization". Both for Case A and case B pressure from clients and practices from other sectors are determined as factors that drives them to phase 2 regarding a data-driven culture. An interviewee from Case B stated: "We experienced pressure from our rentals. One of our responsibilities is to make neighborhoods more livable, data is needed in order to measure that".

A challenge that is particularly strong for both low-maturity cases is taking away resistance to adopt a new technology. An interviewee from case A emphasize this as a barrier to make the shift from level 2 to 3 by saying: "Data and its use is of course a new invention, people don't know the added value of it". Case A also identified the struggle of creating insights derived from analysis. As one interviewee from case A stated: "I should work more data-driven, but in order to do that, analysis has to be made usable in such a way that we can immediately derive insights from it".

Cases $\mathrm{C}$ and D identified external pressure as an important driver to move to phase 3 and create desire to participate and support for change. As one interviewee from case D stated: "Our management had to answer more and more questions coming from outside that they cannot answer without using data". Also emerging innovative players forced this companies to move to phase 3 in their maturity of a data-driven culture to stay ahead of competition. Furthermore, identifying KPI's makes employees able to get insights in their work performance. This increases the desire to work more data-driven. An interviewee from case C stated: "The financial KPI's are really clear, for instance the cost/income ratio is one the most important ones. That makes people able to have insights in the costs and revenues and to steer these by themselves. We also do have these KPI's for HR." Another interviewee from the HR department from the same case confirmed this by saying: "Since we are working with KPI's nowadays, we know if we are performing well, and what we can improve". Within case D young generation is mentioned multiple times as a factor that drives them forward in realizing a change to a data-driven culture. Young people do see the relevance according to an interviewee from case D: "I definitely think it depends on the generation, probably also because of your background. However, age peers who do not have a technical background do also see the relevance of working data-driven. Perhaps the young generation have a better understanding of how to apply data and use a dashboard." Another interviewee within case D expressed this by stating: "But look, I am young, so I adapt very easily". Furthermore, off-site events and education sessions are determined as success factors. For instance, in case $\mathrm{D}$ an off-site to Estonia was organized which was completely in theme of data in order to inspire and make employees more aware of the need to working data-driven. In addition, an interviewee of case D emphasize the importance of an education session: "I think it is very important to let that change live among employees. For instance, a session was organized in which they just walk through the new tooling system and they really explain the added value. By doing this, you ensure everyone is much more open to use it, instead of receiving an email including: 'This is it, and good luck'. I think that is very important in order to realize that change." This expressed as a main success factor by case $\mathrm{C}$ as well.

A relevant challenge companies are facing to move from phase 3 to phase 4 in data-driven culture maturity is the complicated organizational structure. Realizing new initiatives takes so much effort that it forms a barrier in actual change behavior. As one interviewee from case D stated: "I think one of the barriers is to be able to create a strong data-driven culture due to the big spaghetti of systems we are coping with. As a result, it is sometimes just less easy to realize things". Secondly, lack of time forms a barrier among employees from companies who are trying to move forwards from phase 3 to phase 4 . In case $\mathrm{C}$, an interviewee stated the following in response to what would be a barrier for him to actual use data to build his arguments: "My own time that is needed to invest in it". Interviewees from case D expressed this as well.

According to cases $\mathrm{E}$ and $\mathrm{F}$ a driving factor that moves companies to phase 4 in their maturity of a data-driven culture is mainly due to the high priority and strong push from top-management to work datadriven. In case $F$ an interviewee is describing the following as the reason why they moved forward to level 4: "The goals of 2019 stated by the topmanagement are all data-driven, everything must be measurable. That is very clear". An interviewee from case E expressed the significant role of the management as well, he stated: "Data-driven marketing terms comes along in very presentation given by managers on congresses. Working datadriven is certainly being pushed".

Within cases $E$ and $F$ organizational-wide standards and methods are deployed to lead to change and the majority works in a data-driven way. However, some relevant challenges are identified in order to implement this to day-to-day basis across all levels within the organization. An interviewee from case $\mathrm{E}$ stated the following: "There is just a struggle to make some things measurable and mainly to get the actual business value out of it". This lack of knowledge is 
mainly the case in departments were data isn't originally embedded, for instance in the HR department. This is expressed by case F as well: "Lack of knowledge in a department such as HR is the biggest challenge. People who are working in HR want to work with humans, they are not used to work with data, while in finance people get it much faster".

\section{Discussion and future research}

This study has contributed to our understanding of success factors and challenges when creating a data-driven culture.

The first proposition regarding clear communication and an exemplary role from topmanagement is strongly supported by all six cases. In previous research, leadership is considered as an important factor in organizational change and transformations [3], [27], [32]. Now this research provides a contribution to these literature as it shows that the role of top-management is a critical success factor to move forward to higher phases in data-driven culture maturity. Additionally, the cases offer examples and practices of how the role of leadership can contribute. Proposition two, including showing results and creating an understanding of the relevance of data-driven working, is most strongly supported by middle- and high-maturity cases. Expressed through exemplary quotations in section five and in previous studies, communicating the benefits of data-driven decision-making forms an important component in creating a data-driven culture [7], [16]. Furthermore, our findings confirm the positive effect of using change agents to demonstrate initiatives and create a network-like structure. This extends the theory of Kotter (2012) concerning the concept of a dualoperating system, in data-driven transformations. The third proposition regarding openness for experimentation and initiatives is the least strongly supported. Academically, our study responds to the request to further explore data-driven transformations with an explicit focus on culture. Our supported findings provide academic contribution as it shows how change management theories applies in creating a culture in data-driven transformations [37], [36], [39], [33], [31].

The implications of our research are threefold.

First, our findings show the value of adding an additional 'data-driven culture' dimension to our understanding of transformations. This could be as an extension to the DELTA model, but other data driven transformation models could benefit equally. Low maturity would be signified by a culture based on hierarchy and a lack of acknowledgement of the need to change, whereas a high maturity level would be reached when being data-driven is evident in all levels of the organization and implemented in a day-to-day basis.

The second implication highlights the relevant success factors expressed by the cases in order to reach a next phase in data-driven culture maturity. To start the transition successfully following a clear strategy is determined as a success factor to create awareness of the need to change and move forward to the second maturity phase. Both for low- and middlematurity cases external pressure from clients, stakeholders and competitors is established as a factor that drives them to become more mature in their datadriven culture. Clear KPI's, off-site events and educational sessions, are particular identified by middle-maturity cases as factors to successfully reached phase 3 , in which employees are open to participate and support the change [12]. The cases in phase 4 indicate the increased importance of leadership. The push from management to build datadriven argumentations and to set data-driven goals as high priority, is seen as an important success factor by high-maturity cases. Considering previous research expressed the role of leadership as critical component in organizational change, this finding further underlines the prominence of leadership in data-driven transformations [24], [25], [26], [27].

The third implication provides an identification of relevant challenges companies face when moving forward to the next phase in data-driven culture maturity. A challenge that is particularly strong in phase 2 is taking away resistance to adopt a new technology. Besides, there is too little focus on the provision of usable analysis to ensure employees are able to derive insights from it. For both cases in maturity phase 3 the rigid organizational structure forms a critical challenge in their practices to actual change behavior of employees. In addition, employees experienced lack of time they need to invest as a barrier to build data-driven decisions and move forward in their maturity [9]. The cases in phase 4 face a lack of skills in departments in which data-driven methods are not embedded from origin, for instance in HR departments. This forms a challenge to ensure the change is evident in all levels of the organization and to implement data-driven working methods on a dayto-day basis (phase 5) [22], [11], [12], [13].

One of the main limitations of our research is inherent to our case study approach and sample selection: six cases in just a few industries, all in one country. To expand cross-industry comparison and generalizability, more cases representing a broader selection of data-driven transformations are needed. Second, organizational change is influenced by various 
external and internal constraints. As some approaches are effective in particular situations but unsuccessful in others, there is no one best answer in how to organize a data-driven culture and lead your organization through a data-driven transformation. The findings of this study should be considered as possible factors and challenges that influence, rather than the universal best way to manage an organizational change towards data-driven culture maturity.

For future research, the supported propositions, success factors and challenges should be further studied, possibly using a quantitative approach. In addition, as this research found that urgency is mainly determined by external factors, it would be valuable to investigate differences between industries that are relatively stable with those facing disruption. Lastly, it is found that organizational structures influence the maturity towards a data-driven culture. Future research based on a broader selection of cases would be needed to investigate this in more detail.

\section{References}

[1] K. Himmi, J. Arcondara, P. Guan, and W. Zhou, "Value Oriented Big Data Strategy: Analysis \& Case Study," Proc. 50th Hawaii Int. Conf. Syst. Sci., no. January, pp. 10531062,2017

[2] S. Wambaa, A. Gunasekaranb, S. Akterc, S. Rend, R. Dubeye, and S. Childef, "Big data analytics and firm performance: Effects of dynamic capabilities," Journal of Business, 70, 356-365, 2017

[3] A. McAfee and E. Brynjolfsson, "Big data: The Management Revolution.," Harv. Bus. Rev., no. October, pp. $1-9,2012$

[4] K. Schwab, “The Fourth Industrial Revolution”, New York, NY: Penguin Random House, 2017

[5] R. Bean and T. H. Davenport, "Companies are failing in their efforts to become data-driven.," Harv. Bus. Rev., no. February, 2019

[6] M. Gualtieri and N. Yuhanna, "The Forrester Wave TM : Big Data Hadoop,” Forrester research, p. 15, 2014

[7] J. Pfeffer and R. I. Sutton, "Evidence-Based Management," Harv. Bus. Rev., vol. 84, no. 1, pp. 1-12, 2006

[8] C. Anderson, "Creating a data-driven Organization," Sebastopol, CA: O’Reilly Media, 2015
[9] W. Bridges, and S. Mitchell, S., "Leading transition: A new model for change," Leader to leader, 16(3), 30-36, 2000

[10] T.H. Davenport, J.G Harris, and R. Morison, "Analytics at Work: Better Decisions, Better Results," Boston, MA: Harvard Business Publishing, 2010

[11] K. Lewin, "Field Theory in Social Science," New York: Harper \& Row, 1951

[12] J. Hiatt, "A Model for Change in Business, Government and the Community," Loveland, CO: Learning Centre Publications, 2006

[13] E. A. McConnaughy, C.C. DiClemente, Prochaska, J. O., \& Velicer, W. F., "Stages of change in psychotherapy: A follow-up report. Psychotherapy," Theory, Research, Practice, Training, 26(4), 494, 1989

[14] B. Windt, H. Borgman, C. Amrit, "Understanding leadership challenges and responses in data-driven transformations", Proceedings of the $52^{\text {nd }}$ Hawaii International Conference on System Sciences, 2019

[15] S. LaValle, E. Lesser, R. Shcokley, M.S. Hopkins and N. Kruschwitz, "Big Data, Analytics and the Path from Insights to Value," MITSloan Management Review, 2011

[16] R. Cosic, G. Shanks, and S. Maynard, "Toward abusiness analytics capability maturity model," In Proceedings of the 23rd Australasian Conference on Information Systems (ACIS), 1-11, 2012

[17] J. Iversen, P. A. Nielsen, and J. Norbjerg, "Situated assessment of problems in software development," Database for Advances in Information Systems, 30(2), 66-81, 1999

[18] J. Becker, R. Knackstedt, and J. Pöppelbuß, "Developing maturity models for IT management - a procedure model and its application," Business Information Systems Engineering, 1(3), 213-222, 2009

[19] R. Saena, and A. Srinivasan, "Business Analytics: A practitioner's guide,” New York, NY: Springer-Verlag, 2013

[20] M. Comuzzi, and A. Patel, How organizations leverage big data: A maturity model. Industrial Management \& Data Systems, 116(8), 2016

[21] R. Vidgen, S. Shaw, and D. B. Grant, "Management challenges in creating value from business analytics," Eur. J. Oper. Res., vol. 261, no. 2, pp. 626-639, 2017

[22] Prosci, "Best Practices in Change Management," $10^{\text {th }}$ Edition, 2018. 
[23] J.D. Ford, L.W. Ford, and A. D'Amelio, "Resistance to change: the rest of the story," The Academy of Management Review, 33(2), 362-377, 2008

[24] P. Warren, "Big change, best path: successfully managing organizational change with wisdom, analytics and insight," London, UK: Kogan Page, 2014

[25] J. P. Kotter, “A sense of urgency," Boston, MA: Harvard Business Publishing, 2008

[26] T. H. Davenport, and J.G. Harris, "Competing on analytics: The new science of winning," Boston, MA: Harvard Business Publishing, 2007

[27] P. Barth and R. Bean, "Get the Maximum Value Out of Your Big Data Initiative,” HBR Blog Network, 2013

[28] M. Beer, and N. Nitin, "Cracking the Code of Change," Harvard Business Review, 78 (3), 133-141, 2000

[29] M.D. Mumford, G.M. Scott, B. Gaddis, B. and J.M. Strange, "Leading creative people: Orchestrating expertise and relationships," The leadership quarterly, 13(6), 705-750, 2002

[30] W. H. Bommer, G. . Rich, and R. S. Rubin, "Changing attitudes about change: longitudinal effects of transformational leader behavior on employee cynicism about organizational change," J. Organ. Behav., vol. 26, no. 7, pp. 733-753, 2005

[31] K. S. Cameron, and R. E. Quinn, "Diagnosing and changing organizational culture: Based on the competing values framework," John Wiley \& Sons, 2011

[32] B.M. Bass, "Leadership and performance beyond expectations.," New York, NY: Collier Macmillan, 1985

[33] J. Shook, "How to Change a Culture: Lessons from NUMMI," MIT Sloan Management Review, 51 (2), 63-68, 2010
[34] I. Benbasat, D. Gefen, and P. A. Pavlou, "Introduction to the Special Issue on Novel Perspectives on Trust in Information Systems,” MIS Quarterly, 34 (2), 367-371, 2010

[35] N.L. Rodenhouse, T.W. Sherry, and R.T. Holmes, "Site-dependent regulation of population size: a new synthesis," Ecology, 78(7), 2025-2042, 1997

[36] J. P. Kotter, "Leading Change : Why Transformation Efforts Fail,” Harv. Bus. Rev., no. June, 1995

[37] J. Kotter, “Accelerate,” Harv. Bus. Rev., no. November, pp. 1-17, 2012.

[38] C. Holsapple, A. Lee-Post, and R. Pakath, "A unified foundation for business analytics," Decis. Support Syst., vol. 64, pp. 130-141, 2014.

[39] J. P Kotter, and L. A. Schlesinger, "Choosing strategies for change. In Readings in Strategic Management, “" Palgrave, London, (pp. 294-306), 1989

[40] M. Rosemann, and T. de Bruin, "Towards a Business Process Management Maturity Model,” In Bartmann, D., Rajola, F., Kallinikos, J., Avison, D., Winter, R. and EinDor., et al. (Eds). European Conference on Information Systems (ECIS). 26- 28 May, Germany, Regensburg, 2005

[41] R. K. Yin, Qualitative research from start to finish. Guilford Publications, 2018

[42] K. M. Eisenhardt, "Building Theories from Case Study Research Published by: Academy of Management," vol. 14, no. 4, pp. 532-550, 1989.

[43] R. K. Yin, "Case Study Research: Design and Methods," London, UK: SAGE Publications, 2009

[44] D. Berg-Schlosser, G. de Meur, B. Rihoux, and C. C. Ragin, "Qualitative comparative analysis (QCA) as an approach," Thousand Oaks, CA: Sage Publications, 2009 